\title{
Development of Alternative Stabilization Methods for Transportation Infrastructure Based on Geopolymers
}

\author{
Oscar D. Huang ${ }^{1}$, Rinu Samuel ${ }^{2}$, Aritra Banerjee ${ }^{2}$, Anand J. Puppala ${ }^{2,{ }^{*}}$ and Miladin Radovic ${ }^{1, *}$ \\ ${ }^{1}$ Department of Materials Science \& Engineering, Texas A\&M University, College Station, TX 77843-0001 \\ ${ }^{2}$ Department of Civil Engineering, University of Texas at Arlington, Arlington, TX 76019-0001
}

\begin{abstract}
Current soil stabilization methods are often limited by durability and leaching issues and do not always offer sustainable treatments. This research explores the use of geopolymers to stabilize clays in the North Texas area. In recent years, geopolymer has received much attention as an eco-friendly and sustainable alternative to conventional chemical additives, since it can be processed at room temperature from aqueous solutions by utilizing waste materials and/or abounded natural sources. Two subgrade soils from North Texas were treated with GP mix at a ratio of $8 \mathrm{wt} \%$ dry GP to dry soil. GP is shown to reduce swelling and shrinkage potential of soil considerably while an increase in unconfined compressive strength is observed as well. Therefore, further studies are recommended to understand the mechanism of GP and soil bonding resulting in said changes.
\end{abstract}

\section{Introduction}

Transportation infrastructure in Texas and its neighboring states has been frequently built on highly compressible soils, which lack the strength to support structures during their construction or service life. Conventionally, chemical stabilization techniques using cementitious materials and polymers have been used to increase strength and stiffness properties of these soils. Although these chemical stabilization techniques are widely used, they are limited by durability and leaching issues, resulting in infrastructure failure. In addition, currently used soil stabilizers do not offer sustainable and eco-friendly treatments. As such, there is a need for new and improved ground improvement solutions that are sustainable, durable, and enhances the engineering properties of soils for transportation infrastructure. This research explores the use of geopolymers as a soil stabilizer for subgrade soils commonly found in North Texas.

Alumino-silicate binders, known as Geopolymers (GPs), are proposed to be a sustainable and eco-friendly alternative to conventional chemical stabilization techniques [1-3]. GPs harden at ambient temperatures in a relatively short amount of time [4] and can be synthesized by curing activated solutions of various alumino-silicate sources including natural minerals (e.g. clay), their products (e.g. metakaolin), and waste materials (e.g. fly ash, furnace slag, etc.). GPs are known for their high compressive strength and low shrinkage properties, and have been used in recent years as a sustainable alternative to ordinary Portland cement (OPC) in concrete structures, including pavements, bridges, etc. GPs have a much lower carbon footprint than lime and OPC [5] and is therefore more environmentally-friendly than other conventional additives used for soil stabilization. This eco-friendly nature of GPs over conventional chemical stabilizers prompted the present research team to investigate the feasibility of GP for effective stabilization of pavement bases and subgrades.

\section{Methodology}

\subsection{Basic soil characterization}

A testing program which includes basic soil index tests and engineering characterization were conducted based on approved testing standards. Basic index tests conducted include particle size distribution tests (sieve analysis and hydrometer), Atterberg limits, water content and specific gravity, while engineering characterization tests conducted include compaction tests, UCS, free vertical (1-D) swell, and linear shrinkage bar tests. The corresponding standards for each of the tests can be found in Table 1.

Based on the particle size distribution tests, the clay from Lewisville, TX of the Eagle Ford geological formation was classified as a high-plasticity clay $(\mathrm{CH})$, while the clay obtained from Alvarado, TX was classified as a low-plasticity clay (CL), as shown in Table 2. Further tests of Atterberg limits confirmed these results (Table 3 ). Henceforth, the two types of soils will be addressed by their USCS classification.

\footnotetext{
* Corresponding author: anand@uta.edu and mradovic@tamu.edu
} 
Table 1. Basic soil testing program and standards.

\begin{tabular}{|c|c|}
\hline Test Name & Test Standard \\
\hline Particle Size Distribution & ASTM D6913/D6913M-17 \\
\hline Atterberg Limits & ASTM D4318-17 \\
\hline Specific Gravity & ASTM D854-14 \\
\hline Moisture-Density & ASTM D698-12, and \\
Relationship & GR-84-14 \\
\hline Unconfined Compressive & ASTM D166/D2166M-16, \\
Strength & ASTM STP479-EB \\
\hline 1-D Swell Test & ASTM D4546-14 \\
\hline Linear Shrinkage Bar Test & TEX-107-E \\
\hline
\end{tabular}

Table 2. Summary of gradation tests: sieve analysis and hydrometer tests.

\begin{tabular}{|c|c|c|c|c|c|}
\hline $\begin{array}{c}\text { Soil } \\
\text { Location }\end{array}$ & Gravel & Sand & Silt & Clay & $\begin{array}{c}\text { USCS } \\
\text { Classification }\end{array}$ \\
\hline Lewisville & $0.0 \%$ & $9.8 \%$ & $34.3 \%$ & $56.0 \%$ & CH \\
\hline Alvarado & $0.0 \%$ & $33.6 \%$ & $33.9 \%$ & $32.5 \%$ & CL \\
\hline
\end{tabular}

Table 3. Summary of Atterberg limits and specific gravity tests.

\begin{tabular}{|c|c|c|c|c|}
\hline Soil Type & LL (\%) & PL (\%) & PI (\%) & Gs \\
\hline CH & 80 & 27 & 53 & 2.78 \\
\hline CL & 42 & 25 & 17 & 2.69 \\
\hline
\end{tabular}

\subsection{Basic materials characterization}

X-ray diffraction (XRD) was used to confirm the formation of geopolymers, while all samples (i.e. GP treated/untreated CL, metakaolin, and pure GP) were characterized with SEM to better understand the microstructure. XRD analysis was carried out using a Bruker D8 Advance (Bruker AXS Inc, WI) diffractometer with $\mathrm{Cu}-\mathrm{K} \alpha$ radiation source generated at $40 \mathrm{~mA}$ and $25 \mathrm{kV}$, in the $2 \theta$ range of $10-75^{\circ}$ with $2 \theta$ step of $0.02^{\circ}$ and at the rate of 0.4 seconds per step. SEM analyses of all samples were carried out with the JEOL JSM-7500F (JEOL USA Inc, MA) FE-SEM to study the microstructure of the samples. The SEM samples were then sputter coated with $5 \mathrm{~nm}$ of platinum-palladium alloy to avoid charging and to enhance the quality of the analysis.

\subsection{Geopolymer synthesis and treatment of soils}

The GPs used in this research were synthesized by researchers using potassium hydroxide (Mallinckrodt Chemicals, NJ), amorphous fumed silicon (IV) oxide (Alfa Aesar, MA) with $350-410 \mathrm{~m}^{2} / \mathrm{g}$ specific surface area, MetaMax ${ }^{\circledR}$ (BASF Catalysts LLC, NJ) metakaolin, and deionized water. Metakaolin is a purer aluminosilicate source than the more commonly used fly ash and was therefore used as a precursor for GP synthesis in this research.

The potassium hydroxide was dissolved in deionized water to create a highly alkaline solution to process the alkali metal cations. The amorphous fumed silicon oxide was then added to adjust the $\mathrm{Si} / \mathrm{Al}$ ratio of the final product as desired, to create the activating solution for the synthesis of geopolymer. The activating solution was then mixed with metakaolin, which is a high-purity activating aluminosilicate source in a high-sheared mixer for 6 minutes to synthesize GP.

Since GP is a complex multi-parameter materials system with parameters that depend on each other, the preliminary study primarily determined the relationship between mixability and water ratio for both sodium and potassium-based GP. It is worth noting that increasing water and silica content decreases viscosity and increases curing time, and that sodium-based GP are more viscous than potassium-based GP at the same water content. Taking into account of all these different parameters as well as the mechanical properties from Lizcano et al. [4], it was decided that GP with molar ratio of $\mathrm{Si} / \mathrm{Al}=2$, Water:Solids $=2$, and $\mathrm{Al} / \mathrm{K}=1$ (GPID: K431) would produce the best candidates to maximize both strength and mixability/workability for soil stabilization.

The XRD results in Figure 1 demonstrate that selected methodology of synthesizing pure GP indeed does produce GP. As can be seen, the characteristic amorphous hump from $2 \theta \max \approx 22^{\circ}$ for the metakaolin to the $2 \theta_{\max } \approx 27-30^{\circ}$ for the cured geopolymer [6]. While the sharp peaks at $2 \theta \approx 27.5^{\circ}, 2 \theta=38^{\circ}$, and $2 \theta=$ $48^{\circ}$ correspond to the crystalline non-reactive $\mathrm{TiO}_{2}$ in anatase phase (PDF number $=00-034-0180$ ) which is a known impurity that was already in the metakaolin [4]. The SEM results of pure metakaolin and K431 GP are presented later for morphology comparison with untreated and treated soils.

The K431 GP mix was used to stabilize CL at an OMC of $20 \%$, at a concentration of $6.6 \%$ by weight of the soil at OMC. Henceforth, the term 'treated samples' indicates samples treated with the K431 GP mix at the said concentration. Treated samples were cured and tested for UCS, shrinkage, swell and Atterberg limits. For UCS testing, treated CL samples were cured for a period of 7 and 28 days, under two different curing methods. One set of treated CL samples were cured for 7 days in a moisture room by misting at $100 \%$ relative humidity (RH), while the second set of treated samples were cured in $100 \% \mathrm{RH}$ for 3 days and then air-dried at about $21^{\circ} \mathrm{C}\left(70^{\circ} \mathrm{F}\right)$ for the remainder of the 4 days. The same was done for samples cured for 28 days as well, where some samples were cured for 28 days in $100 \%$ relative humidity (RH), while others were cured in $100 \%$ RH for 14 days and then air-dried at about $21^{\circ} \mathrm{C}\left(70^{\circ} \mathrm{F}\right)$ for the remainder of the 14 days. Untreated CL samples were also cured in $100 \%$ RH for 7 days, after which both treated and untreated samples were subject to UCS testing.

\section{Results}

The basic index and engineering characterization tests conducted on procured subgrade soils revealed the need for stabilization to enhance the strength of these soils. Moisture-density relationship curves were established 
for both treated and untreated subgrade soils. It is observed that treated soils have a higher OMC and lower
MDD values as expected and is shown in Figure 2.

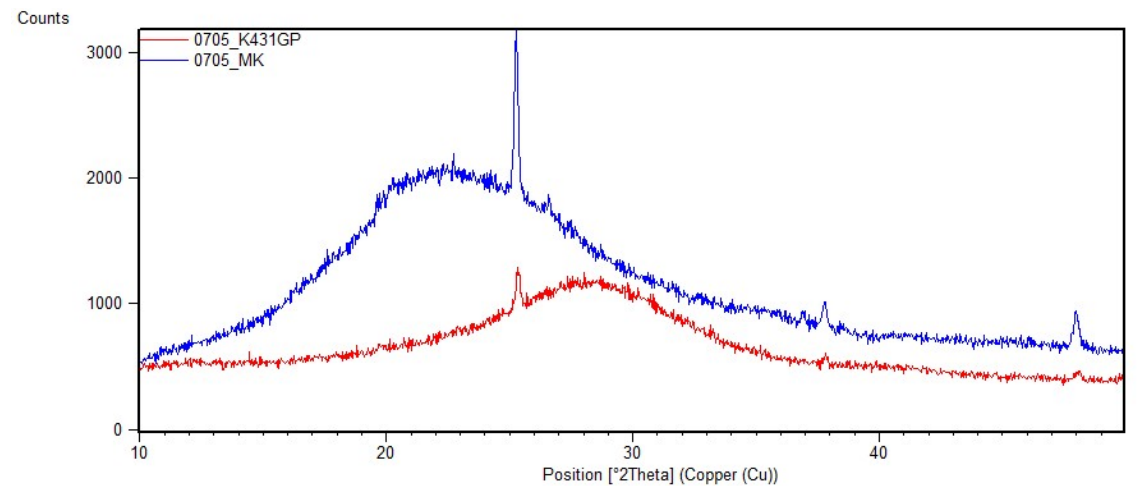

Fig. 1. XRD of metakaolin (blue, top) and K431 geopolymer (red, bottom).

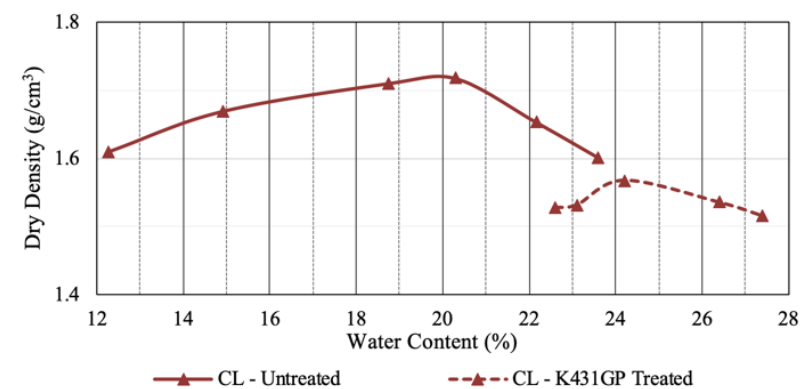

Fig. 2. Moisture-density curves for treated and untreated subgrade soils.

Linear shrinkage tests were conducted on treated CL as well as $\mathrm{CH}$ samples, both of which indicated that GP treatment resulted in significant reduction of shrinkage compared to untreated samples, as is visually observed in Figure 3. Treated $\mathrm{CH}$ and $\mathrm{CL}$ samples showed a decrease in shrinkage from $21.6 \%$ to $7.3 \%$ and from $16.7 \%$ to $13.1 \%$, respectively.

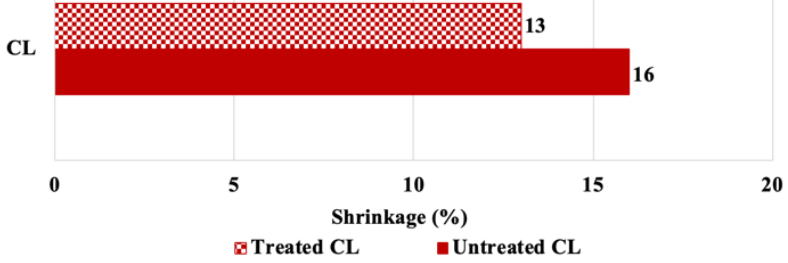

Fig. 3. Shrinkage plot of untreated and GP treated subgrade soils.

Atterberg limit tests conducted on treated CL samples showed that GP treatment of CL resulted in a $72 \%$ reduction in its PI, from 25 to 7 . In addition, Swell tests on treated $\mathrm{CL}$ and $\mathrm{CH}$ samples indicated a

significant reduction in vertical swell strain from $0.9 \%$ and $8.8 \%$, respectively to $0.04 \%$.

The UCS of treated CL samples cured in $100 \% \mathrm{RH}$ for a period of 7 and 28 days showed some strength increase (in the range of 50-75\%) compared to the UCS of untreated samples, while the second set of samples that were air-dried for part of the curing period showed significant increase in UCS (in the range of 400-700\%) compared to untreated samples (Figure 4). Samples cured for 28 days show that the UCS plateaus after 7 days as there is only about an $18 \%$ increase from the strength of 7-day cured samples. Elastic modulus was calculated from the linear portion of the UCS stressstrain curves and was found to be significantly higher (in the range of $100-300 \%$ ) for GP treated samples as compared to untreated samples at OMC. The increase in UCS strength of air-dried specimens ranges from 75 psi to $100 \mathrm{psi}$, which is higher than the minimum requirement for the chemical treatment to be considered effective (50 psi as per ASTM D4609-94). Note that, the treated and cured specimen were observed to disintegrate and slake when soaked in water.

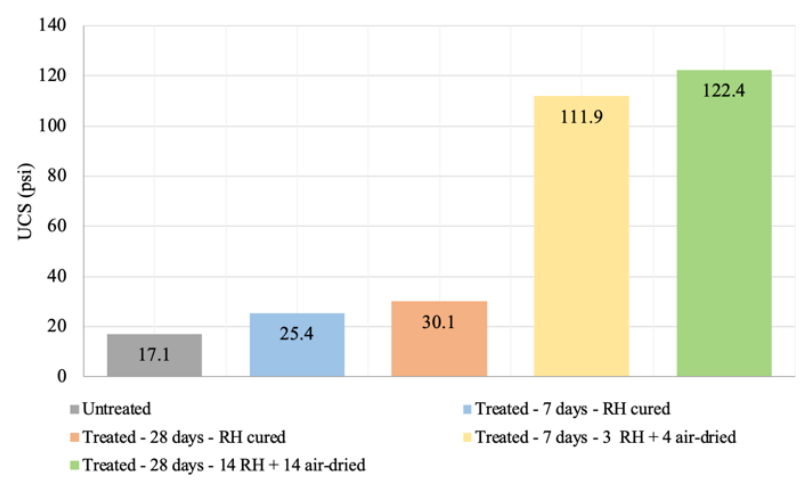

Fig. 4. UCS test results of untreated and treated samples cured for 7 days using 2 curing methods.

The SEM images in Figure 5 shows the micromorphology of untreated CL, metakaolin, and pure K431 GP, and treated CL. As expected, the untreated CL contains various sizes of clumps, but does not have any overall cohesiveness resulting in the low strength. The morphology of metakaolin is taken as a reference to find any unreacted particles. Since GP has an amorphous structure (recall the amorphous hump seen in XRD in Figure 1), a gel-like structure is seen throughout the sample with some micro-cracks, voids, and small looser particles, which are most likely the unreacted components from metakaolin. However, no particles that resembles the metakaolin particles were found in the GP samples. The morphology of treated CL showed more 
resemblance to the morphology of GP than it does to untreated $\mathrm{CL}$, this is an indication that the current processing technique does produce GP within the treated sample. However, there are a significant amount of unbounded material and microcracks shows signs of potential improvement in properties if the amount of these imperfections could be significantly reduced.

(a)

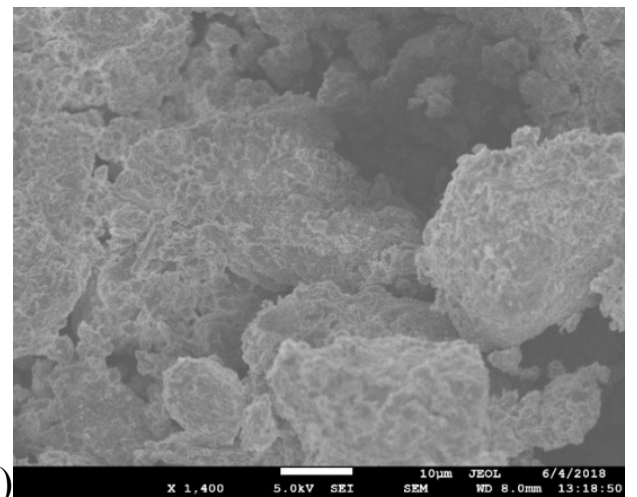

(b)

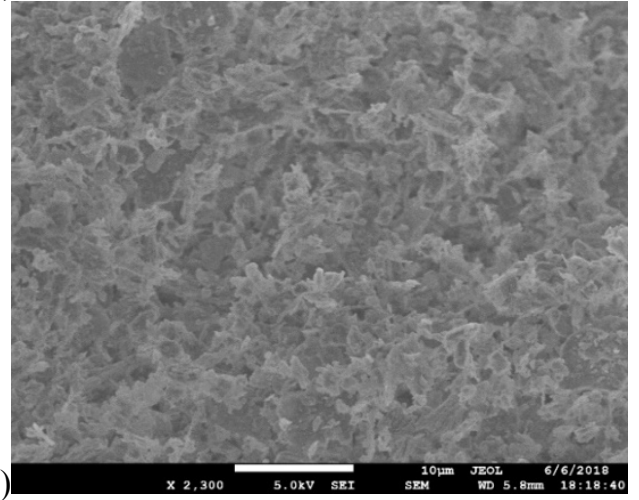

(c)

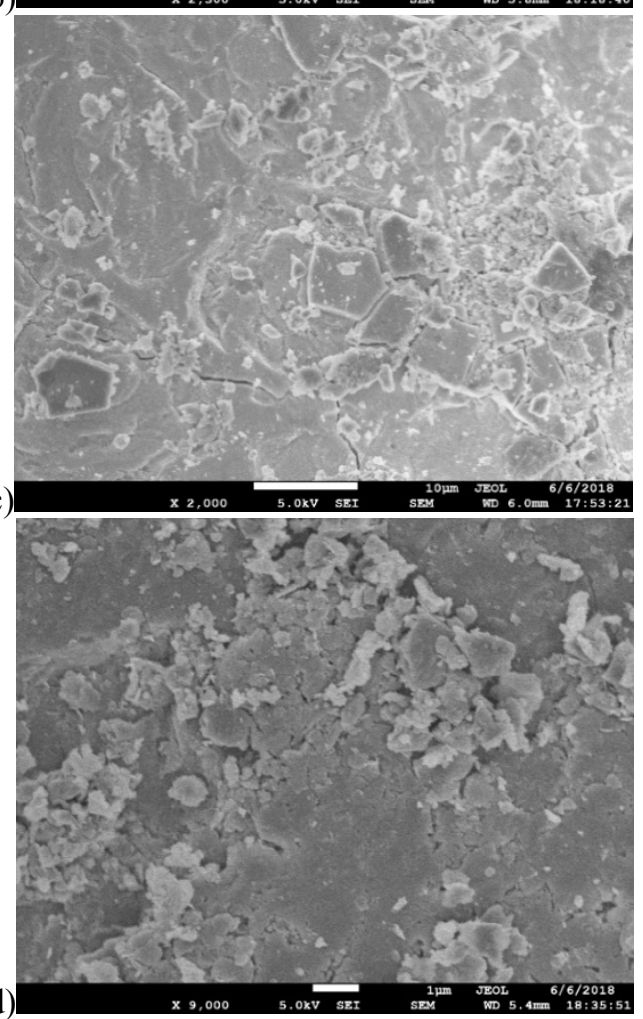

Fig. 5. SEM images of: (a) CL, (b) Metakaolin, (c) K431 GP, (d) K431 GP + CL

\section{Conclusions and recommendations}

This pilot study explores the use of metakaolin-based geopolymer for the stabilization of native North Texas subgrade soils. Two subgrade soils from North Texas were acquired for this study, a high-plasticity clay and a low-plasticity clay. The low-plasticity clay was chosen to study the preliminary effects of geopolymers, based on unconfined compression strength (UCS), swell, and shrinkage tests. Soils were mixed with the K431 GP mix at a ratio of $8 \mathrm{wt} \%$ dry GP to dry soil. The following conclusions can be drawn from the study results:

- Shrinkage tests show that geopolymer treated soils are efficient in reducing shrinkage, without developing cracks.

- Swell tests show that the swell potential of the soil is mitigated within acceptable limits, on treating with GP.

- GP treatment of soils is shown to have an increase in the UCS of subgrade soils.

- GP treatment of soils was found to reduce the shrink-swell potential of soils significantly, which is a major concern for high PI soils.

Further studies are recommended to validate the wide-scale application of GP as a sustainable soil stabilizer for high PI soils.

Based on this study, it is recommended that parameters affecting GP strength, such as dry GP to dry soil ratio, GP composition, processing methods, and alkali-activator, be varied, to observe its influence on the engineering characteristics of GP treated subgrade soils. Micro-characterization tests like Differential Scanning Calorimetry (DSC) would enable in providing a more conclusive direction into the behavior of the material particles. Furthermore, durability studies as well as sustainability metrics and life-cycle cost analysis studies would be useful in practical implementation of this soil stabilization method.

\section{References}

1. Davidovits, J. (1991). Geopolymers: inorganic polymeric new materials. Journal of Thermal Analysis and calorimetry, 37(8), 1633-1656. doi: 10.1007/BF0912193

2. Phummiphan, I., Horpibulsuk, S., Sukmak, P., Chinkulkijniwat, A., Arulrajah, A., Shen, S.L. (2016). Stabilisation of marginal lateritic soil using high calcium fly ash-based geopolymer. Road Materials and Pavement Design, 17(4), 877-891. doi: 10.1080/14680629.2015.1132632

3. Zhang, M., Guo, H., El-Korchi, T., Zhang, G., Tao, M. (2013). Experimental feasibility study of geopolymer as the next-generation soil stabilizer. Construction and Building Materials, 47, 14681478. doi: 10.1016/j.conbuildmat.2013.06.017

4. Lizcano, M., Gonzalez, A., Basu, S., Lozano, K., Radovic, M. (2012). Effects of Water Content and Chemical Composition on Structural Properties of Alkaline Activated Metakaolin-Based Geopolymers. 
Journal of the American Ceramic Society, 95(7), 2169-2177. doi: 10.1111/j.1551-2916.2012.05184.x

5. Gartner, E. (2004). Industrially interesting approaches to "low-CO2" cements. Cement and Concrete Research, 34(9), 1489-1498. doi: 10.1016/j.cemconres.2004.01.021

6. Williams, R.P., Hart, R.D., Van Riessen, A. (2011). Quantification of the Extent of Reaction of Metakaolin-Based Geopolymers Using X-Ray Diffraction, Scanning Electron Microscopy, and Energy-Dispersive Spectroscopy. Journal of the American Ceramic Society, 94(8), 2663-2670. doi: 10.1111/j.1551-2916.2011.04410.x 